\section{Effects of UCS intensity during continuing coterminous delay conditioning on conditioned acceleration during maintained avoidance}

DAVE RIESS and LOUIS K. MARTIN, Galesburg State Research Hospital, Galesburg, Ill. 61401

In a systematic replication of an earlier investigation demonstrating a monotonic relationship between UCS intensity and conditioned acceleration, four rats were run in a multiple schedule with aversive classical conditioning (light-shock pairings) and Sidman shuttlebox avoidance. Each $S$ was given one of four UCS intensities in the first component and run in the second until mean rates of acceleration had stabilized over five sessions. This procedure was repeated for the remaining intensities. Conditioned acceleration again proved to be monotonically related to intensity. Two procedural innovations were able to sustain acceleration permanently and eliminate inhibition of delay.

Earlier, Martin \& Riess (in press) found that increases in avoidance elicited by a CS previously paired with an aversive stimulus were monotonically related to the intensity of that stimulus. The following is a systematic replication (Sidman, 1960a) of this, varying the following five parameters: (a) coterminous delay conditioning (i.e., CS offset = US offset) was employed rather than the discrete delay (i.e., CS offset = US onset) paradigm; (b) the number of classical conditioning trials per session was changed from 25 to 12; (c) two new UCS intensities, 1.25 and 2.9 , were substituted for .58 and 1.9 used previously; (d) classical conditioning was continued for the duration of testing rather than being discontinued just prior to testing; and (e) the avoidance contingencies were in effect during testing whereas they had been omitted previously.

Secondarily, an attempt was made to establish conditioned acceleration as a permanent phenomenon in contrast to a previous report (Sidman, 1960b) by varying the conditions under which it is produced. This involved the combining of classical and operant conditioning into a single experimental session (multiple schedule), with the CS presentations reinforced during the first component (classical) but unreinforced in the second component (avoidance). Also, the CS-US intervals were varied during classical conditioning to see whether inhibition of delay (Rescorla, 1967) could be eliminated.

\section{SUBJECTS}

Subjects were four naive male Wistar rats from the colony maintained by the Psychology Laboratory at the Galesburg State Research Hospital. They were housed in individual cages and were between 72 and 80 days old at the start of the experiment.

\section{APPARATUS}

The apparatus consisted of a shock generator, scrambler, and modified Miller-Mowrer shuttlebox described previously (Kamano \& Arp, 1964).

\section{PROCEDURE}

Subjects were run through the following four-step sequence and were required to meet two 5-day avoidance stability criteria at Steps 1,2, and 3 before proceeding.

(1) Avoidance acquisition consisted of daily 30-min Sidman avoidance sessions with a response-shock (RS) interval of $30 \mathrm{sec}$, a shock-shock (SS) interval of $5 \mathrm{sec}$, and a shock intensity of $1.5 \mathrm{~mA}$.

(2) Preliminary classical conditioning was alternated with avoidance for 8 days and consisted of 12 coterminous light-shock pairings per session. The US was a $5-\mathrm{sec}$ shock. The CS-US intervals were variable in length and randomized for order. For Session 1, all intervals were $5 \mathrm{sec}$; for Session 2, six each were given at 5 and $10 \mathrm{sec}$; for Session 3, four each were given at 5,10 , and $20 \mathrm{sec}$; and for Session 4, three each were given at $5,10,20$, and $40 \mathrm{sec}$. The intertrial interval was also variable with randomized values of $90 \mathrm{sec}(4)$, $120 \mathrm{sec}(4)$, and $150 \sec (4)$.

(3) Multiple schedule pretest. Procedures 1 and 2 were next combined into a single session. The first component (classical) was identical to Step 2 except that the terminal schedule of CS-US intervals became effective (VI $16 \mathrm{sec}$ ), which consisted of two intervals each of $5,10,20$, and $40 \mathrm{sec}$ and four intervals of $60 \mathrm{sec}$. The compartment divider, lowered in the first component to prevent abortive avoidances, was then raised, serving as the exteroceptive stimulus signalling the onset of the second component and allowing free responding between compartments. The second (operant) component was identical to Step 1.

(4) Testing was identical to Step 3 except that unreinforced CS presentations occurred in the 5th, 10th, 15th, 20th, 25th, and 30 th $\mathrm{min}$ of avoidance. A daily acceleration ratio was computed from the formula A.R. $=4 A /(4 A+B)$, where $A=$ total CS responding and $B=$ total "nonCS" responding. Each $S$ was run at Step 4 until this ratio was stable (a range of no greater than .05 over 5 consecutive days) at which time it was recycled to Step 3 and reconditioned to the subsequent intensity. The intensities used in this study were .25 , $1.25,2.85$, and $4.9 \mathrm{~mA}$. The order of presentation for these intensities was descending for three $S$ s and ascending for S 6. No attempt was made to control for ordering effects since these failed to occur in the previous study (Martin \& Riess, in press) and since the liberal 5-day pretest period provided ample opportunity for any such effects to adapt out.

\section{RESULTS}

A preliminary analysis was made of the effectiveness of the VI Pavlovian schedule in preventing inhibition of delay, a phenomenon known to occur with long fixed-interval (FI) Pavlovian conditioning (Rescorla, 1967). Avoidance responding was separately recorded for each half of all CS intervals during the 5 stable days of the last 11 performances. The first half of the interval contained $52.3 \%$ of all CS responding, indicating that the VI schedule had been effective in distributing the excitatory properties of the CS throughout the interval and preventing inhibition of delay. The VI schedule therefore

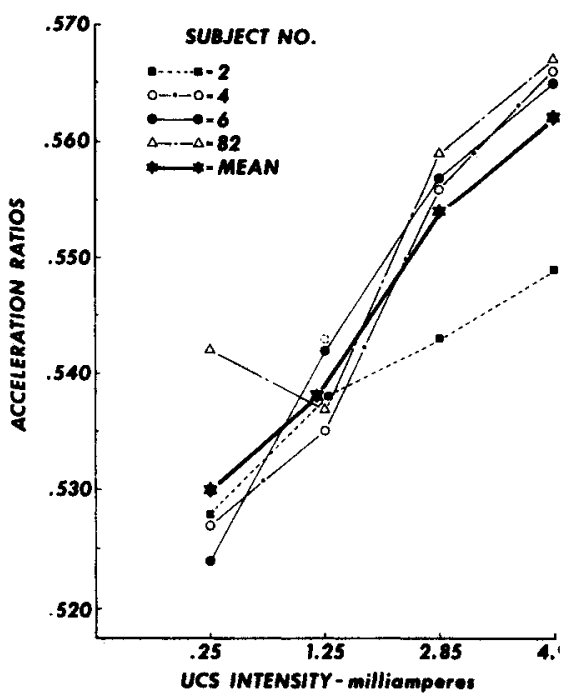

Fig. 1. Individual and mean performances of four Ss. The broken circle is a rerun for S 6. 
recommends itself for general use in studies where uniform responding over longer $\mathrm{CS}$ presentations is desired and where rate measures are more critical than latency measures.

The data on the acceleration ratios in relation to UCS intensity are presented in Fig. 1.

A repeated measures analysis of variance (Winer, 1962) indicated that the shock intensity variable had a highly significant effect on the acceleration ratios ( $F=24.41$, $\mathrm{p}<.001$, $\mathrm{df}=3,9$ ). In addition, a trend analysis showed that the relationship between UCS intensity and the acceleration ratios was strongly monotonic, the $\mathrm{F}$ ratios being $71.47, .24$, and 1.47 for the linear, quadratic, and cubic trend components, respectively. Furthermore, application of the Omega test (Hays, 1963) to the data demonstrated that the shock intensity variable accounted for $84 \%$ of the within-S variance.

In addition, the nearly identical performances of $S 6$ for two exposures at $1.25 \mathrm{~mA}$, separated by 2 months with intervening exposure to two other intensities, add weight to the stability criterion used here as a fair index of terminal performance. The fact that these two performances $(.542$ and .543) were preceded by exposure to the highest and lowest intensities, while not ruling out ordering effects, at least suggests that such effects either adapt out during the 5 days preceding testing or that they affect only preterminal performance.

\section{DISCUSSION}

The results of the present study seem to contrast with the findings of the previous Martin \& Riess (in press) study in that the magnitude of the ratios at the two comparable intensities was considerably greater in the first study (at .25, the mean ratio was .552 in the first study and .530 in this one. At 4.9, the mean ratio was .632 in the first study and .562 in the second.) These differences in absolute magnitude of the ratios appear to be a function of whether the avoidance contingencies are in effect or inoperative. In the initial study, testing was conducted under extinction conditions. A common occurrence under these conditions was for a CS presentation to be superimposed on a baseline of less than two responses per minute, the minimum required to avoid all shocks in the second study. The actual CS responding as such was thus more comparable for the two studies than the ratios suggest, owing to the artifact of depressed baselines obtained during extinction.

Secondly, Sidman, who first reported the phenomenon (Sidman, Herrnstein, \& Conrad, 1957) later reported (1960) that it eventually fails to occur. This contrasts with present results in that under the present conditions, the phenomenon was being reliably elicited in all Ss as late as 6 months following its initial occurrence and gave every indication of being indefinite. This discrepancy is predictable from Sidman's (1960) own account of the phenomenon. He considers acceleration a type of superstitious avoidance behavior. The fact that his procedure resulted in transitory increases only is attributed to the fact that shocks were included at the termination of the CS during avoidance, whereas in the present study they were included separately and omitted during avoidance. If a somewhat facetious distinction can be made between "successful" and "unsuccessful" superstitions, the impermanence of the phenomenon he reports is predictable from the fact that the increased avoidance rates failed to avoid the stimulus-contingent shock, rendering it in effect an extinction paradigm. In the present conditions, however, the stimulus-contingent shock was inoperative during avoidance; increased responding during the light successfully "avoided" the stimulus-contingent shock and the paradigm became a sort of spurious or S-defined avoidance procedure. Ss in the present study, then, were superstitiously reinforced for their avoidance increases by the shock omissions; in the Sidman et al procedure, this "reinforcement" failed to occur and acceleration eventually extinguished.

In this respect, conditioned acceleration is diametrically contrasted with conditioned suppression of appetitive responding. In the latter case, the phenomenon will continue indefinitely when the shocks are included during appetitive responding. It will eventually vanish if the Pavlovian reinforcement occurs separately and the shocks are excluded during appetitive responding. Precisely inverse relationships hold between inclusion vs exclusion of the Pavlovian contingencies and the permanence or impermanence of the phenomenon in conditioned acceleration.

\section{REFERENCES}

HAYES, W. L. Statistics for psychologists. New York: Holt, Rinehart, \& Winston, 1963.

KAMANO, D. K., \& ARP, D. J. Effects of chlordiazepoxide (Librium) on the acquisition and extinction of avoidance responses. Psychopharmacologia (Berlin), 1964, 6, 112-119.

MARTIN, L., \& RIESS, D. Effects of UCS intensity during preliminary discrete delay conditioning on conditioned acceleration during avoidance extinction. Journal of Comparative \& Physiological Psychology, in press.

RESCORLA, R. A. Inhibition of delay in Pavlovian fear conditioning. Journal of Comparative \& Physiological Psychology, 1967, 64, 114-120.

SIDMAN, M. Tactics of scientific research. New York: Basic Books, 1960a.

SIDMAN, M. Normal sources of pathological behavior. Science, 1960b, 132, 61-68.

SIDMAN, M., HERR NSTEIN, R. J., \& CONRAD, D. G. Maintenance of avoidance behavior by unavoidable shocks. Journal of Comparative \& Physiological Psychology, 1957, 50, 553-557. WINER, B. J. Statistical principles in experimental design. New York: MoGraw-Hill, 1962.

\section{Discriminative classical conditioning of excitement anticipatory to food reward}

EDWARD ZAMBLE, Queen's University at Kingston, Ont., Canada, and C. RICHARD KIRKWOOD, University of Washington Medical School, Seattle, Wash. 98105

Rats were trained with a discriminative Pavlovian paradigm while activity was measured. As in previous studies, an increase in activity occurred to CSt, but it was also found that activity wasless during $C S$ - than during a randomly unpaired stimulus. Contacts at the foodcup were also measured, and found to occur during CSt, mostly at times of least activity.
Pairing of a signal with noncontingent delivery of food leads to increased activity during the signal (Sheffield \& Campbell, 1954). However, the effects of a CS- have not been demonstrated.

It has been argued (e.g., Zamble, 1967) that the increased activity to a CS+ reveals a Pavlovian process which underlies the working of reinforcement in instrumental reward situations. Similarly, it is possible that responses to discriminative stimuli for nonreward may be mediated by inhibition of excitement by a Pavlovian CS-. Thus the present study incorporated a discriminative classical conditioning procedure in order to assess its effects on activity. 